Article

\title{
Game Analysis of Determinants of Stability of Semiconductor Modular Production Networks
}

\section{Wei He $^{1, *}$ and Si-Hua Chen ${ }^{2}$}

1 School of Business Administration, Jiangxi University of Finance and Economics, No.168, East Shuanggang Road, Changbei, Nanchang 330013, China

2 Institute of Information Resource Management, School of Information Technology, Jiangxi Key Laboratory of Data and Knowledge Engineering, Jiangxi University of Finance and Economics, No.168, East Shuanggang Road, Changbei, Nanchang 330013, China; E-Mail: chensihua@jxufe.edu.cn

* Author to whom correspondence should be addressed; E-Mail: hewei@jxufe.edu.cn; Tel.: +86-135-7693-0621; Fax: +86-791-8381-6813.

Received: 30 April 2014; in revised form: 9 July 2014 / Accepted: 21 July 2014 /

Published: 29 July 2014

\begin{abstract}
In today's rapidly changing environment, semiconductor manufacturers compete more in the area of modular production networks. However, the instability of semiconductor modular production networks can to a large extent lead to the failure of these networks. The aim of this paper is to discuss the significance and explore the maintenance of the stability of these semiconductor modular production networks. Firstly, this paper qualitatively and quantitatively defines the stability of semiconductor modular production networks. Based on this, by establishing game models, this paper analyzes the influence mechanism of the main factors: external market fluctuation, the internal benefit allocation mechanism, and opportunism, which can jeopardize the stability of these networks. We find that: the greater the benefits a member enterprise derives from the common benefits, the more likely it is the member enterprise will not exit the modular production network; the adaptive ability of the networks to the external environment is closely related to the stability of the modular production networks; the supervision and punishment in networks can be substituted for each other and the level of supervision, punishment and trust can exert great influence on the stability of semiconductor modular production networks. Lastly, we propose some specific suggestions.
\end{abstract}

Keywords: semiconductor industry; modular production network; stability; game analysis 


\section{Introduction}

As one of the fastest developing and most influential industries in the world, it is recognized that the semiconductor industry has greatly promoted the development of the world economy and technologies. According to the most recent statistics of the American Semiconductor Industry Association, sales within the global semiconductor industry in 2013 reached 305.6 billion dollars and its growth rate is about $4.8 \%$, the highest on record. As a technological-intensive and capital-intensive industry, and in view of its leading role in electronic information industries, the technological level of a nation's semiconductor industry usually represents the nation's position in the global electronic information industries. What is more, the development of the semiconductor industry is always regarded as a symbol of a nation's modern economy and high-tech power. On a whole, its push-effect on technology and science can be summarized as:

(1) It works as a leading industry in high-tech industries. In information industries, semiconductors are in the core position. Usually, a one-dollar output value of the semiconductor chips drives a 10-dollar output value of the related information industries. It is regarded as an industry with the highest added value as well as the core industry of high-tech industries.

(2) It has wide coverage. The electronic industries usually cover telecommunication, computer, electron, home appliance, automobile and aerospace industries, etc. As we know, semiconductors are widely used in all of these fields. Therefore, there is no doubt that the development of these industries cannot be achieved without the support of the semiconductor industry.

(3) It has low energy consumption. According to the report "Semiconductor technology: the potential to revolutionize U.S. energy productivity" issued by American Council for an Energy-Efficient Economy (ACEEE) in 2009, the deployment of semiconductor technologies has generated a net savings of about 775 billion kilowatt-hours ( $\mathrm{kWh}$ ) of electricity in the year 2006 alone and this is in the order of a 20 percent savings for the entire U.S. economy. Therefore, the semiconductor industry features as a low energy and environmental friendly industry, that occupies a small area of land and which can promote the transformation of the production of small sized and low energy products.

(4) It can stimulate social employment. The semiconductor industry can provide millions of positions for technological workers and increase the employment of related industries many folds.

(5) It has high profits. According to the statistics of American stock market, the price-earning ratio of the semiconductor industry, real estate industry and automotive manufacturing industry are respectively $42 \%, 35 \%$, and $13 \%$. The returns on investment of the three industries are $14 \%$, $2.6 \%$, and $3.7 \%$, respectively. From the comparison, we can see the profitability and return on investment of the semiconductor industry is far higher than that of the automotive manufacturing and real estate industries.

(6) It can promote the upgrading of industries. As we know, the huge electronic information industries of China mainly rely on the production of low value-added home appliances and OEM (Original Equipment Manufacturer) of foreign brands. The development of the semiconductor industry can greatly promote the upgrading of related electronic information industries and the nation's transformation to high-tech and innovative society. 
For the above reasons, the development of the semiconductor industry has received much attention. However, nowadays competitions are no longer those just between enterprises. Instead, it is more the competition between the cooperation networks formed by manufacturing enterprises. As Baldwin and Clark claimed, with the increased complexity of modern technology, modularity is becoming more important today [1]. Modularity is a very general set of principles for managing complexity, by breaking up a complex system into discrete pieces, which can communicate with one another through standardized interfaces within a standardized architecture [2]. Electronic information products such as the computer are considered products in which modularity is most widely used for technological design [3]. Now the application of the idea of modularity is connected not only to technological design but also to organizational design. Sanchez and Mahoney pointed out that modularity in the design of products may lead to - or at least ought to lead to - modularity in the design of the organizations that produce such products [4]. By analyzing the cases of automobile companies and computer companies, Langlois argued that the modularity design would lead to the vertical and horizontal decomposition of industrial organization [2]. Rather than handing suppliers detailed instructions, manufacturers now give suppliers interface specifications and then encourage them to produce the parts by forming their own network of dozens of suppliers for this module [1]. Sturgeon called this kind of new form to organize production the modular production network and regarded it as a new industrial organization form [5]. Thanks to its advantages such as quickly integrating resources, better adaptation to environment and enhancement of core competency, modular production networks have much vitality. For semiconductor enterprises, establishing stable and effective modular production networks is the key path to constructing competitive advantage in such a rapidly changing environment [6]. However, what kinds of factors may affect the operation of a stable and effective semiconductor modular production network? Furthermore, how do these factors exert influence on the modular production network? All these questions are very important for establishing and maintaining a stable and effective modular production network. However, the studies of these questions are not enough. Especially, the mechanism of how these factors influence the stability of semiconductor modular production networks is awaiting further exploration.

Based on the literature review of semiconductor modular production networks, this paper analyzes the main factors, which influence the stability of semiconductor modular production networks. By constructing game models, this paper further explores the influence mechanism of these factors on the stability of semiconductor modular production networks. Based on the results of the game analysis, this paper proposes specific measures and suggestions for the stability of semiconductor modular production networks, which are supposed to be valuable for managers.

This paper proceeds as follows: based on literature review, the second part explains what stability is and discusses the main factors, which may influence the stability of semiconductor modular production networks; the third section first builds a model to evaluate the degree of stability of modular production networks. Then, it constructs game models to analyze how common payoff, opportunism, trust and punishment affect the stability of semiconductor modular production networks; based on the results of the game analysis, the forth section proposes competitive strategies for managers to build stable semiconductor modular production networks and states the weaknesses of this paper as well as further work. 


\section{Stability and Determinants of Stability of Semiconductor Modular Production Network}

\subsection{Stability of Semiconductor Modular Production Network}

For the definition of stability, there are different understandings from different disciplines.

From a systems control perspective, the classical definition about stability is: for small interferences, if the influence on the operation is also small, then the state which is not influenced can be classed as stable; In contrast, for small interferences, if the influence on the operation is great, the state of the operation is labeled unstable [7,8]. Therefore, in systems theory, the stability of a system is mainly referring to the ability of a system to return to the initial state after being interfered with and the ability of a system to resist the outside interferences.

From a physics perspective, stability is often regarded as a system that is reaching equilibrium and the orderly operation of a system [9]. The orderly operation of a system depends on whether the related factors can form a dynamic equilibrium state by interacting with each other.

From an ecology perspective, on the one hand, stability refers to the ability of an ecological system to resist and avoid the outside interferences and sabotage- the resistance. On the other hand, stability refers to the ability of an ecological system to return to the initial state after being interfered with - the resilience [10]. Usually, the energy and materials in an ecological system flow in a balanced way and, at the same time, the structure of an ecological system also remains stable. This is called ecological balance.

For production networks, their dynamics are subject to different perturbations due to changes in the market, changes in customer behaviors, information and transport congestions, unreliable elements of the networks, etc. [11]. Therefore, the stability of modular production network refers to the normal fluctuation state of a harmonious networking relationships maintained by member enterprises in a modular production network for given production goals [12]. The stability usually has two meanings: one indicates relatively dynamic stability [11]. As an open and dynamic system, modular production networks will change with the market. After the goal is achieved and needs are changed, the networking relationship will be adjusted accordingly. Secondly, it indicates the harmonious and fluctuated stability [13], for the networking relationship is always subject to change, movement and conflict, only when all the members in the network think the benefits they can get from the network are bigger than the cost to terminate the relationship, will they remain in the network, and the state is stable.

\subsection{Determinants of Stability of Semiconductor Modular Production Network}

The studies on the stability and instability of modular production networks are mainly carried out from systems theory, economics, strategic management and sociology perspectives.

From a systems theory perspective, modular production networks are highly complex systems. The management aspects they are involved in include several enterprise nodes and several kinds of activities. Usually, these node enterprises have different management modes, preferences, values or even individual emotions and bounded rationalities, which endow the cooperation network with a multi-leveled and multi-structured systematic feature [14]. What is more, comparing with one individual enterprise, cooperation network is a more open and dynamic system, which has a very close 
relationship with the environment $[15,16]$. Any change in external environment will affect the realization of the whole function of the system and make the network full of uncertainty [17].

From an economics perspective, given both parties in the cooperation are pursuing their own interests, the transaction cost theory holds the view that the opportunistic behaviors in enterprise cooperation is unavoidable. On the one hand, the appearance of opportunistic behaviors will lead both sides to harm the overall interests of the whole network as well as the interests of their partners. They can reduce the degree of trust and cooperation level [18]. On the other hand, to reduce the bad effect of opportunistic behaviors on the cooperation alliance both sides will take related measures such as implementing complete contracts and enhancing the supervision of the cooperation process. Obviously, these behaviors will increase the transaction cost of the cooperation network [19]. When the increase of transaction costs of cooperation is high enough to offset the payoff brought by cooperation, the instability of the network will be unavoidable.

From a strategic management perspective, most empirical studies pointed out that the need for the complementary resources was very important impetus for enterprises to cooperate. The resource dependence theory thinks the existence of an organization needs resources. However, an organization usually cannot have all the resources it needs. It has to interact with the factors of the environment it depends on while most of these factors exist in another organization [20-22]. The key point of management of the core enterprise in a cooperation network on node enterprises is to reduce its dependence on its partners if possible and increase its partners' dependence on it in order to gain the control over the network and obtain the most benefits from the network. For the node enterprises, they intend to improve their positions through cooperation to gain greater benefits. Hence, under such conditions, the extent of dependence of both sides and the extent of power balance of both sides can easily cause the changes of the structure of the cooperation network and therefore influence the stability of the network.

From a sociology perspective, the influence of the noneconomic factors such as the reputation and trust arising out of cooperation from the stability of the cooperation network is of much interest. Studies show that given the market uncertainty and changes, the noneconomic factors such as position and reputation are regarded as the main factors for individual enterprise to maintain mutual dependence and networking contractual relationships [23-25]. When the market is uncertain, enterprises tend to increase their dependence on outside cooperators who are recognized as trustworthy [26,27].

From the above analysis, we can conclude that there are mainly four factors, which influence the stability of the modular production network.

(1) The diversified interests. In all kinds of cooperation networks, the goals member enterprises are pursuing are not the same or even in conflict. For this reason, it is very probable that member enterprises may harm the collective interests to maximize their own interests.

(2) The asymmetry of information. Especially in modular production networks, the manufacturing integrators and module suppliers possess their own private information. The asymmetry of information will bring moral risk and adverse selection risk.

(3) The uncertainty of external environments. The environment enterprises are facing is complex and changing. Therefore, the performance of enterprises is unavoidably influenced by uncontrollable factors. Thereby, the uncontrollable environment is also regarded one of the main factors influencing the stability of the cooperation network. 
(4) Human beings' bounded rationality and uncertainty of transaction. Because of human beings' bounded rationality and uncertainty of transactions, the contracts are incomplete. Therefore, members in cooperation networks always demonstrate opportunistic and free-ride behavior.

Based on the above analysis, we can find that the core problems that may influence the stability of modular production networks are the allocation of common payoff, the changes in the external market, opportunistic behaviors, punishment and trust. Aiming at these problems, we construct game models to further explore the mechanism of how these factors affect the stability of modular production networks.

\section{Game Models of Stability of Semiconductor Modular Production Networks}

In this section, we establish game models to analyze the influence of determinants on the stability of semiconductor modular production networks.

\subsection{Measure of Stability of Semiconductor Modular Production Networks}

For member enterprise $i$ of a modular production network, it faces such kinds of decision as either staying in the modular production network or exiting. Suppose staying in the modular production network can bring the utility $U_{i}$, and suppose if the enterprise uses the resources once occupied by the modular production network for other investments, it can get the utility $U_{i a l}$, where the switching cost is $U_{\text {itran }}$. Based on the two kinds of utilities, the enterprise can make a decision:

$\left\{\begin{array}{l}\text { Stay in the modular production network } U_{i} \geq U_{i a l}-U_{\text {itran }} \\ \text { Exit the modular production network } U_{i}<U_{i a l}-U_{i t r a n}\end{array}\right.$

Of course, no matter which decision the enterprise makes, the real utility is uncertain and we can only estimate its range. We suppose the distribution functions of $U_{i}, U_{\text {ial }}, U_{\text {itran }}$ are $f_{i}(x), f_{i a l}(x)$, $f_{\text {itran }}(x)$. Their joint distribution function is $f_{i, \text { itran,ial }}\left(x_{1}, x_{2}, x_{3}\right)$. The range for the enterprise to choose to exit is $\Omega=\left\{\left\{x_{1}, x_{2}, x_{3}\right\} \mid U_{j}<U_{i a l}-U_{\text {itran }}\right\}$. Therefore, the probability for enterprise $i$ to exit is $\mathrm{P}\{$ Enterprise $i$ exit $\}=\int_{\Omega} f_{\text {i,itran,ial }}\left(x_{1}, x_{2}, x_{3}\right) d \Omega$.

Because $U_{i a l}, U_{\text {itran }}$ and $U_{i}$ cannot coexist, $U_{i a l}$ and $U_{\text {itran }}$ are respectively independent from $U_{i}$. Therefore, $f_{i, \text { itran,ial }}\left(x_{1}, x_{2}, x_{3}\right)=f_{i}\left(x_{1}\right) f_{\text {itran,ial }}\left(x_{2}, x_{3}\right)$, where $f_{\text {itran,ial }}\left(x_{2}, x_{3}\right)$ is the joint distribution function of $U_{i a l}$ and $U_{\text {itran }}$. Thereby,

$$
\mathrm{P}\{\text { Enterprise } i \text { not exit }\}=\int_{-\infty} d x_{2} \int_{-\infty}^{+\infty} f_{\text {itran, } i a l}\left(x_{2}, x_{3}\right) d x_{3} \int_{-\infty}^{x_{3}-x_{2}} f_{i}(x) d x_{1}
$$

This is the probability for enterprise $i$ to stay. If at any stage of the modular production network all the member enterprises choose to stay, then the modular production network is stable. Therefore, we call the probability of a member enterprise not to exit the degree of stability of the modular production network. If one factor can change some variable in Equation (1) to make $\mathrm{P}$ \{Enterprise $i$ not exit become bigger (or smaller), we believe the factor can increase (or reduce) the degree of stability of the modular production network. 
3.2. Game Model of Stability of Semiconductor Modular Production Networks Influenced by Network Payoff

\subsubsection{Basic Assumptions}

The payoff of a modular production network can be divided into private payoff and common payoff. We suppose there are two enterprises in the modular production network: enterprise 1 and enterprise 2. The sum of their private payoff is $Y_{0}=y_{10}+y_{20}$ and the sum of the common payoff of the modular production network is $Y$. The total sum of these payoffs is $Y_{0}+Y$. Suppose the percentage the common payoff enterprise 1 can get is $\alpha$, then the payoff of the two enterprises in the modular production network are:

Enterprise 1: the total payoff is $y_{1}=y_{10}+\alpha Y$

Enterprise 2: the total payoff is $y_{2}=y_{20}+(1-\alpha) Y$

These payoffs are closely related to time. We suppose the time we get the market payoff is $t_{k}$. Then, the value of $y_{10}, y_{20}$ and $Y$ at the time of $t_{k}$ is respectively $y_{10}\left(t_{k}\right), y_{20}\left(t_{k}\right)$, and $Y\left(t_{k}\right)$.

Suppose the time series $y_{10}(t), y_{20}(t)$, and $Y(t)$ obey the random process.

$$
\begin{gathered}
y_{10}\left(t_{k}\right)-y_{10}\left(t_{k-1}\right)=a_{1}-b_{1} t_{k}+\sigma_{1} \sqrt{\left(t_{k}-t_{k-1}\right)} e_{1}(k) \\
y_{20}\left(t_{k}\right)-y_{20}\left(t_{k-1}\right)=a_{2}-b_{2} t_{k}+\sigma_{2} \sqrt{\left(t_{k}-t_{k-1}\right)} e_{2}(k) \\
Y\left(t_{k}\right)-Y\left(t_{k-1}\right)=a-b t_{k}+\sigma \sqrt{\left(t_{k}-t_{k-1}\right)} e(k)
\end{gathered}
$$

where, $k=1,2,3 \ldots$;

$a_{1}, b_{1}, b_{2}, a, b, \sigma_{1}, \sigma_{2}, \sigma>0, e_{1}(k), e_{2}(k)$ are independent normal random variables.

$a_{1}, a_{2}, a$ denote the increase of payoff of these semiconductor enterprises with the continuous development of the product and organizational scale of these enterprises. They show the high growth feature of the semiconductor enterprises.

$b_{1}, b_{2}, b$ denote with the development of technology and time, the decrease of payoff of the semiconductor enterprises due to the reduced use and production of the old products. Furthermore, the bigger $t$ is, the bigger the rate of decent is. Therefore, this shows the low life span feature of semiconductor products.

$\sigma_{1}, \sigma_{2}, \sigma, e_{1}(k), e_{2}(k)$ shows the high-risk feature of semiconductor industry. Specifically, $\sigma_{1}, \sigma_{2}, \sigma$ denote the market fluctuation risk coefficient, which shows the degree of risk brought by market fluctuation. $e_{1}(k), e_{2}(k), e(k)$ denote the risk payoff of different stages brought by changes of external factors. From (2)-(4), we can get the payoff at $t_{k}$ :

The private payoff of enterprise 1 is:

$$
\begin{aligned}
& y_{10}\left(t_{k}\right) \\
& =a_{1}-b_{1} t_{k}+\sigma_{1} \sqrt{\left(t_{k}-t_{k-1}\right)} e_{1}(k)+y_{10}\left(t_{k-1}\right) \\
& =2 a_{1}-b_{1}\left(t_{k}+t_{k-1}\right)+\sigma_{1}\left[\sqrt{\left(t_{k}-t_{k-1}\right)} e_{1}(k)+\sqrt{\left(t_{k-1}-t_{k-2}\right)} e_{1}(k-1)\right]+y_{10}\left(t_{k-2}\right)
\end{aligned}
$$




$$
=(k-m) a_{1}-b_{1} \sum_{i=m+1}^{k} t_{i}+\sigma_{1} \sum_{i=m+1}^{k}\left[e_{1}(i) \sqrt{\left(t_{i}-t_{i-1}\right)}\right]+y_{10}\left(t_{m}\right)
$$

where $k=1,2,3,4 \ldots ; m$ is a positive integer, and $1 \leq m \leq N$.

Similarly, the private payoff of enterprise 2 is:

$$
y_{20}\left(t_{k}\right)=(k-m) a_{2}-b_{2} \sum_{i=m+1}^{k} t_{i}+\sigma_{2} \sum_{i=m+1}^{k}\left[e_{2}(i) \sqrt{\left(t_{i}-t_{i-1}\right)}\right]+y_{20}\left(t_{m}\right)
$$

The common payoff of the modular production network is:

$$
Y\left(t_{k}\right)=(k-m) a-b \sum_{i=m+1}^{k} t_{i}+\sigma \sum_{i=m+1}^{k}\left[e(i) \sqrt{\left(t_{i}-t_{i-1}\right)}\right]+Y\left(t_{m}\right)
$$

The total payoff the enterprise gets at $t_{k}$ from the modular production network is comprised of the private payoff and the amount of payoff the enterprise get from the common payoff of the modular production network. Therefore, the total payoff of enterprise 1 at $t_{k}$ is:

$$
\begin{aligned}
& y_{1}\left(t_{k}\right)=y_{10}\left(t_{k}\right)+\alpha Y\left(t_{k}\right) \\
& =(k-m) a_{1}-b_{1} \sum_{i=m+1}^{k} t_{i}+\sigma_{1} \sum_{i=m+1}^{k}\left[e_{1}(i) \sqrt{\left(t_{i}-t_{i-1}\right)}\right]+y_{10}\left(t_{m}\right) \\
& +\alpha\left\{(k-m) a-b \sum_{i=m+1}^{k} t_{i}+\sigma \sum_{i=m+1}^{k}\left[e(i) \sqrt{\left(t_{i}-t_{i-1}\right)}\right]+Y\left(t_{m}\right)\right\} \\
& =(k-m)\left(a_{1}+\alpha a\right)-\left(b_{1}+\alpha b\right) \sum_{i=m+1}^{k} t_{i} \\
& +\sum_{i=m+1}^{k}\left[\sigma_{1} e_{1}(i) \sqrt{\left(t_{i}-t_{i-1}\right)}+\alpha \sigma e(i) \sqrt{\left(t_{i}-t_{i-1}\right)}\right]+y_{10}\left(t_{m}\right)+\alpha Y\left(t_{m}\right)
\end{aligned}
$$

Similarly, the total payoff enterprise 2 gets at $t_{k}$ is:

$$
\begin{aligned}
& y_{2}\left(t_{k}\right)=y_{20}\left(t_{k}\right)+\alpha Y\left(t_{k}\right) \\
& =(k-m) a_{2}-b_{2} \sum_{i=m+1}^{k} t_{i}+\sigma_{2} \sum_{i=m+1}^{k}\left[e_{2}(i) \sqrt{\left(t_{i}-t_{i-1}\right)}\right]+y_{20}\left(t_{m}\right) \\
& +(1-\alpha)\left\{(k-m) a-b \sum_{i=m+1}^{k} t_{i}+\sigma \sum_{i=m+1}^{k}\left[e(i) \sqrt{\left(t_{i}-t_{i-1}\right)}\right]+Y\left(t_{m}\right)\right\} \\
& =(k-m)\left[a_{2}+(1-\alpha) a\right]-\left[b_{2}+(1-\alpha) b\right] \sum_{i=m+1}^{k} t_{i} \\
& +\sum_{i=m+1}^{k}\left[\sigma_{2} e_{2}(i) \sqrt{\left(t_{i}-t_{i-1}\right)}+(1-\alpha) \sigma e(i) \sqrt{\left(t_{i}-t_{i-1}\right)}\right]+y_{20}\left(t_{m}\right)+(1-\alpha) Y\left(t_{m}\right)
\end{aligned}
$$

Suppose the life span of the modular production network is $\mathrm{T}=t_{N}$ We study the stability of the modular production network at certain stage. That is, we mainly consider whether the network enterprises will make the exit decision at that stage. We can calculate the expected payoff of the network enterprise at the stage. For example, at $t_{m}$ the expected payoff of enterprise 1 is: 


$$
\begin{aligned}
& E\left\{\sum_{k=m+1}^{N}\left[y_{10}\left(t_{k}\right)+\alpha Y\left(t_{k}\right)\right]\right\} \\
& =\sum_{k=m+1}^{N} E\left[(k-m)\left(a_{1}+\alpha a\right)-\left(b_{1}+\alpha b\right) \sum_{i=m+1}^{K} t_{i}+\sum_{i=m+1}^{k}\left[\sigma_{1} e_{1}(i) \sqrt{\left(t_{i}-t_{i-1}\right)}+\alpha \sigma e(i) \sqrt{\left(t_{i}-t_{i-1}\right)}\right]+y_{10}\left(t_{m}\right)+\alpha Y\left(t_{m}\right)\right] \\
& =\frac{1}{2}(N-m+1)(N-m)\left(a_{1}+\alpha a\right)-\left(b_{1}+\alpha b\right) \sum_{k=m+1}^{N} \sum_{i=m+1}^{k} t_{i}+\left(y_{10}\left(t_{m}\right)+\alpha Y\left(t_{m}\right)\right)(N-m)
\end{aligned}
$$

where,

$$
\begin{aligned}
& y_{10}\left(t_{m}\right)+\alpha Y\left(t_{m}\right) \\
& =m\left(a_{1}+\alpha a\right)-\left(b_{1}+\alpha b\right) \sum_{i=t}^{m} t_{i}+\sum_{i=1}^{m}\left[\sigma_{1} e_{1}(i) \sqrt{t_{i}-t_{i-1}}+\alpha \sigma e(i) \sqrt{t_{i}-t_{i-1}}\right]+y_{10} t_{0}+\alpha Y\left(t_{0}\right)
\end{aligned}
$$

3.2.2. Stability of Semiconductor Modular Production Network Influenced by External Market Fluctuation

Suppose $U_{1 a l}-U_{1 \text { tran }}=U_{\text {1const }}$, which denotes the net utility enterprise 1 has when it exits the network and invests in other opportunities. To study the influence of external market fluctuation on the stability of the modular production network, we suppose other factors are given except for $\sigma_{1}, \sigma_{2}, \sigma$ and the utility the enterprise gets is the payoff. Then, the probability of enterprise 1 choosing not to exit or the degree of stability of the network is the probability of enterprise 1 when the expected value of the expected payoff of enterprise 1 in the network currently is bigger than the net utility of exiting the network.

$$
\begin{aligned}
& P\{\text { enterprise } 1 \text { not exit }\} \\
& \left.=P\left\{\sum_{k=m+1}^{N}\left[y_{10}\left(t_{k}\right)+\alpha Y\left(t_{k}\right)\right]\right\} \geq U_{1 \text { const }}\right\} \\
& =P\left\{\begin{array}{l}
\sum_{i=1}^{m}\left[\sigma_{1} e_{1}(i) \sqrt{t_{i}-t_{i-1}}+\alpha \sigma e(i) \sqrt{t_{i}-t_{i-1}}\right] \\
\left.\geq U_{1 \text { const }}-\left[m\left(a_{1}+\alpha a\right)-\left(b_{1}+\alpha b\right) \sum_{i=1}^{m} t_{i}+y_{10}\left(t_{0}\right)+\alpha Y\left(t_{0}\right)\right](N-m)\right\} \\
-\frac{1}{2}(N-m+1)(N-m)\left(a_{1}+\alpha a\right)+\left(b_{1}+\alpha b\right) \sum_{k=m+1}^{N} \sum_{i=m+1}^{k} t_{i}
\end{array}\right\} \\
& =P\left\{\begin{array}{l}
(N-m) \sqrt{t_{i}}\left(\sigma_{1} e_{1}+\alpha \sigma e\right) \\
\geq U_{1 \text { const }}-\left[m\left(a_{1}+\alpha a\right)-\left(b_{1}+\alpha b\right) \sum_{i=1}^{m} t_{i}+y_{10}\left(t_{0}\right)+\alpha Y\left(t_{0}\right)\right](N-m) \\
1
\end{array}\right\}
\end{aligned}
$$

where $e_{1}$ and $e$ obey the standard normal distribution with the average value is 0 and thevariance is 1 .

We discuss on $P$ \{enterprise 1 not exit\}. From Equation (12) we can get: the bigger the market fluctuation faced by the network enterprises is or the bigger the $\sigma_{1}$ and $\sigma$ is, the smaller the value of 
$P$ \{enterprise 1 not exit\}, or we can say the smaller the degree of stability of the modular production network is. Thereby, based on this, we can draw the conclusion: given other factors, the stronger the external market fluctuation is, the weaker the stability of the network. An example is the influence of the Japanese earthquake in 2011 on the semiconductor modular production networks. The Japanese earthquake and tsunami that occurred in 2011 not only heavily hit the Japanese economy but also greatly influenced the global semiconductor industrial supply chain. The heavily affected area-the northeast of Japan - is the location of many semiconductor wafer fabrication plants. Therefore, the unexpected external market factors - the earthquake and tsunami-greatly affected many important semiconductor suppliers such as Toshiba, Renesas electronics, and Fujitsu and caused instability in the semiconductor modular production networks which are formed by these semiconductor producers and the wafer fabrication plants. What is more, from Equation (12) we can see: by exerting the influence on the degree of external market fluctuation, $\alpha, \sqrt{t},(N-m)$ can indirectly influence the degree of stability of the modular production network. The bigger $N$ is or the longer the expected life span of the network is, the bigger $(N-m)$. Then, it is hard to know the expected payoff and therefore the network is more unstable. For example, for the semiconductor modular production network formed by Intel and its module suppliers, when the competition in the digital TV chip market becoming more fierce, if both parties expect longer cooperation with each other, in fact the expected payoffs for each is very unstable and we can predict such a modular production network will therefore be very unstable. Furthermore, in 2011, Intel exited the digital TV chip market. For $\alpha$, we can hardly know its influence on the stability of the network for other items also have $\alpha$.

3.2.3. Stability of Semiconductor Modular Production Network Influenced by the Internal Benefit Allocation Mechanism

To further study the influence of $\alpha$ on the stability of the modular production network, for both sides of Equation (10), the derivative of E with respect to $\alpha$ is:

$$
\begin{aligned}
& \frac{\partial E\left\{\sum_{k=m+1}^{N}\left[y_{10}(t k)+\alpha Y(t k)\right]\right\}}{\partial \alpha} \\
& =\frac{1}{2}(N-m+1)(N-m) a-b \sum_{k=m+1}^{N} \sum_{i=m+1}^{k} t_{i}+\left(-b \sum_{i=1}^{m} t_{i}+\sum_{i=1}^{m}\left[\sigma e(i) \sqrt{t_{i}-t_{i-1}}\right]+Y\left(t_{0}\right)\right)(N-m)
\end{aligned}
$$

Making it equal to 0 , then

$$
\frac{1}{2}(N-m+1) a-b\left(\frac{1}{(N-m)} \sum_{k=m+1}^{N} \sum_{i=m+1}^{k} t_{i}+\sum_{i=1}^{m} t_{i}\right)+\left(\sum_{i=1}^{m}\left[\sigma e(i) \sqrt{t_{i}-t_{i-1}}\right]+Y\left(t_{0}\right)\right)=0
$$

From $E\left[Y\left(t_{k}\right)-Y\left(t_{k-1}\right)\right]=0$, we can get the solution $t^{*}=\frac{a}{b}$. Below, we will further discuss the significance of the value: 


$$
t^{*}=\frac{\frac{1}{(N-m)} \sum_{k=m+1}^{N} \sum_{i=m+1}^{k} t_{i}+\sum_{i=1}^{m} t_{i}}{\frac{1}{2}(N-m+1)+\frac{1}{a}\left(\sum_{i=1}^{m}\left[\sigma e(i) \sqrt{t_{i}-t_{i-1}}\right]+Y\left(t_{0}\right)\right)}
$$

(1),

If,

$$
\begin{aligned}
& t>\frac{\frac{1}{(N-m)} \sum_{k=m+1}^{N} \sum_{i=m+1}^{k} t_{i}+\sum_{i=1}^{m} t_{i}}{\frac{1}{2}(N-m+1)+\frac{1}{a}\left(\sum_{i=1}^{m}\left[\sigma e(i) \sqrt{t_{i}-t_{i-1}}\right]+Y\left(t_{0}\right)\right)}, \\
& \frac{\partial E\left\{\sum_{k=m+1}^{N}\left[y_{10}\left(t_{k}\right)+\alpha Y\left(t_{k}\right)\right]\right\}}{\partial \alpha}>0
\end{aligned}
$$

When $\alpha$ increases, $E\left\{\sum_{k=m+1}^{N}\left[y_{10}\left(t_{k}\right)+\alpha Y\left(t_{k}\right)\right]\right\}$ will increase. That means when the expected payoff of enterprise 1 increases, the probability of enterprise 1 choosing to exit will reduce. It indicates that if the transformation of the market from growth to recession is late enough and the percentage of common payoff the enterprise can get from the network is bigger, then the probability of the enterprise choosing to exit the network is smaller and the network is more stable.

(2),

If,

$$
t<\frac{\frac{1}{(N-m)} \sum_{k=m+1}^{N} \sum_{i=m+1}^{k} t_{i}+\sum_{i=1}^{m} t_{i}}{\frac{1}{2}(N-m+1)+\frac{1}{a}\left(\sum_{i=1}^{m}\left[\sigma e(i) \sqrt{t_{i}-t_{i-1}}\right]+Y\left(t_{0}\right)\right)},
$$$$
\frac{\partial E\left\{\sum_{k=m+1}^{N}\left[y_{10}\left(t_{k}\right)+\alpha Y\left(t_{k}\right)\right]\right\}}{\partial \alpha}<0
$$

Under this condition, when $\alpha$ increases, $E\left\{\sum_{k=m+1}^{N}\left[y_{10}\left(t_{k}\right)+\alpha Y\left(t_{k}\right)\right]\right\}$ will reduce. That is, when the expected payoff of enterprise 1 reduces, the probability of enterprise 1 choosing to exit will become bigger. That means, if the transformation of the market from growth to recession happens earlier and the percentage of common payoff the enterprise can receive from the network is bigger, then the probability of the enterprise choosing to exit is bigger and the network is more unstable. In the early 1990s, thanks to its innovation in production, the cheap labor force and the improvement of capability, the Japanese semiconductor producers had greatly enlarged their market share of DRAM (Dynamic Random Access Memory). In contrast, the DRAM market for the American semiconductor producers was continuing to decline. Represented by Intel, some big American semiconductor producers, who occupied dominance in their modular production networks and always got large percentage of the 
common payoff, took the initiative to give up the DRAM market and exit the DRAM modular production network and turned to invest in MPU R\&D and production.

Apart from that, we also notice that for $\alpha$ and $1-\alpha$, one increases and the other will reduce. Therefore, no matter the value of $t *$, one enterprise increases its probability to exit the network, the other one will reduce the probability. Therefore, $\alpha$ cannot be too big or too small. As we know, semiconductors are produced in networks. Different semiconductor companies such as professional design companies, IP suppliers, chipless processing enterprises, and foundries work together and form complex semiconductor production networks. In these modular production networks, the division of labor is very clear. Usually, the American companies are occupying the high value-added component such as the design of non-storage semiconductors while most processing and packaging work is outsourced to Asian companies. Take the Taiwanese companies as an example. In 1980s, Taiwanese companies were engaged to produce chips for the American semiconductor companies. Through several years' development, Taiwan had become the OEM base for the global semiconductor industry. However, at that time, because of the lack of advanced technology, most Taiwanese semiconductor OEMs could only focus on the low-end production part and only obtained very modest profits compared to the large profits of American companies. Therefore, the dissatisfaction with the benefits allocation mechanism in the cooperation with American companies caused the modular production networks to be very unstable. On the one hand, the Taiwanese OEM strenuously devoted themselves to improving their capability by upgrading the networks or even establishing their own modular production networks to compete with those of the American companies. On the other hand, the low-end manufacturing work was transferred to some other Asian countries such as China and India, which have low labor costs and relatively low technology levels. Therefore, we can see that the imbalanced benefits allocation in the networks is an important factor, which can cause the instability of modular production networks and can lead to some changes. Therefore, only when it is maintained at equilibrium, the stability of the network can be maintained while the equilibrium point depends on the development stage, the common payoff of the network and percentage the enterprise can get from the common payoff [28].

\subsection{Game Model of Stability of Semiconductor Modular Production Networks Influenced by Opportunism, Trust, Supervision and Punishment}

\subsubsection{Basic Assumptions}

Opportunism is defined as the enterprise harming the common payoff of the network or the payoff of other network enterprises to obtain private payoff. Suppose the percentage of common payoff enterprise 1 can get is $\alpha$. Enterprise 1 can get the opportunistic payoff $S_{10}$ by taking opportunistic behaviors and damaging the private payoff of its partners is $-S_{20}$. That is to say, enterprise 1 can get the private payoff $S_{10}+\frac{\alpha}{1-\alpha} S_{20}$ by taking on opportunistic behaviors, and its damage to the common payoff of the network is $-\frac{S_{20}}{1-\alpha}$. Based on this, we suppose opportunism indicates that the enterprise hurts the common payoff of the network to obtain extra private payoff. 
Suppose if there is no opportunism, the common payoff of the modular production network is $Y$. The percentage of common payoff enterprise 1 can get is $\alpha$. The private payoffs of both enterprise 1 and enterprise 2 are 0 . The self-learning payoff of the modular production network is $V$ and each member enterprise can get this payoff. When taking on opportunistic behavior, to obtain $S_{10}$ enterprise 1 will cause the network loss $-S_{1 t}$ and get the punishment $O_{1}\left(S_{1 t}\right)$. Under the same condition, to obtain $S_{20}$, enterprise 1 will lead to the network loss $-S_{2 t}$. The probability of being found is $P_{2}\left(S_{2 t}\right)$ and the punishment is $\mathrm{O}_{2}\left(S_{2 t}\right)$.

where $O_{1}\left(S_{1 t}\right)=a_{p} S_{1 t}+b_{p}, O_{2}\left(S_{2 t}\right)=a_{p} S_{2 t}+b_{p}$.

We further suppose no matter whether it is enterprise 1 or enterprise 2 , their damage to the common payoff has the upper limit $S_{t o p} . \beta_{1 t}=\frac{S_{10}}{S_{1 t}}$ is a constant and only when $\beta_{1 t}>\alpha$ enterprise 1 can get some payoff by taking on opportunistic behaviors.

Suppose the probability of being found is $P_{1}\left(S_{1 t}\right)=\frac{S_{1 t}}{S_{t o p}}, P_{2}\left(S_{2 t}\right)=\frac{S_{2 t}}{S_{t o p}}$.

The trust level of the modular production network refers to the fact that the member enterprises believe that their partners will not take opportunistic behaviors for trivial benefit and themselves, and will furthermore not behave opportunistically for trivial benefits. We use $S_{b}$ to denote the trust level of the network: as long as the benefits the enterprise get by taking opportunistic behaviors are no more than $S_{b}$, opportunistic behavior will not occur.

Suppose the supervision cost enterprise 2 has to pay is $M_{1}<M_{1 \max }$. Then, it will increase the probability of enterprise 1 being found to demonstrate opportunism $S_{1 t}$ to $\frac{S_{1 t}+\frac{M_{1}}{M_{1 \max }}\left(S_{t o p}-S_{1 t}\right)}{S_{t o p}}$. Suppose the supervision efforts enterprise 1 has to invest in are $M_{2}<M_{2 \max }$. Then, it will increase the probability of enterprise 1 being found to demonstrate opportunism $S_{2 t}$ to $\frac{S_{2 t}+\frac{M_{2}}{M_{2 \max }}\left(S_{\text {top }}-S_{2 t}\right)}{S_{\text {top }}}$. Now, we can design the dynamic game model between the two member enterprises:

(1)Enterprise 1 and enterprise 2 make the decision at the same time about taking on opportunistic behaviors.

Enterprise 1 can choose not to take on opportunistic behaviors, namely $S_{l t}=0$ or choose to take on opportunistic behaviors, namely $S_{1 t} \neq 0$.

At the same time, enterprise 2 also can choose not to take on opportunistic behaviors, namely $S_{2 t}=$ 0 or choose to take on opportunistic behaviors, namely $S_{2 t} \neq 0$.

(2)The evolution of the network.

(a) if the strategy of the two enterprises under (1) is $\left(S_{1 t}, S_{2 t}\right)=(0,0)$, then the network can be maintained. At that time, the payoffs of the two enterprises are respectively:

$$
\begin{gathered}
W_{1}=\alpha Y+V-M_{2} \\
W_{2}=(1-\alpha) Y+V-M_{1}
\end{gathered}
$$


(b) if the strategy of the two enterprises under $(1)$ is $\left(S_{1 t}, S_{2 t}\right)=(\neq 0,0)$, there are two situations according to whether the opportunistic behaviors of enterprise 1 are found:

I The opportunistic behaviors of enterprise 1 are not found. The probability is

$$
1-\frac{S_{1 t}+\frac{M_{1}}{M_{1 \max }}\left(S_{t o p}-S_{1 t}\right)}{S_{\text {top }}} \text {. }
$$

The payoff of enterprise 1 is

$$
W_{1}=\alpha Y+V-M_{2}+\left(\beta_{1 t}-\alpha\right) S_{1 t}
$$

The payoff of enterprise 2 is

$$
W_{2}=(1-\alpha) Y+V-M_{1}-(1-\alpha) S_{1 t}
$$

II The opportunistic behaviors of enterprise 1 are found. The probability is

$$
\frac{S_{1 t}+\frac{M_{1}}{M_{1 \max }}\left(S_{t o p}-S_{1 t}\right)}{S_{t o p}} .
$$

Under this condition, suppose enterprise 1 is punished and enterprise 2 is compensated. However, the network cooperation is ended and they cannot obtain the expected payoff.

Then, the payoff enterprise 1 can get is

$$
W_{1}=\left(\beta_{1 t}-\alpha\right) S_{1 t}-O_{1}\left(S_{1 t}\right)-M_{2}
$$

The payoff enterprise 2 can get is

$$
W_{2}=-(1-\alpha) S_{1 t}+O_{1}\left(S_{1 t}\right)-M_{1}
$$

Therefore, under the condition of (b), the expected payoff enterprise 1 and enterprise 2 can get is:

$$
\begin{gathered}
W_{1}=\frac{S_{\text {top }}-\left[S_{1 t}+\frac{M_{1}}{M_{1 \max }}\left(S_{t o p}-S_{1 t}\right)\right]}{S_{t o p}}(\alpha Y+V)+\left(\beta_{1 t}-\alpha\right) S_{1 t}-\frac{S_{1 t}+\frac{M_{1}}{M_{1 \max }}\left(S_{t o p}-S_{1 t}\right)}{S_{t o p}} O_{1}\left(S_{1 t}\right)-M_{2} \\
W_{2}=\frac{S_{t o p}-\left[S_{1 t}+\frac{M_{1}}{M_{1 \max }}\left(S_{t o p}-S_{1 t}\right)\right]}{S_{t o p}}[(1-\alpha) Y+V]-(1-\alpha) S_{1 t}-\frac{S_{1 t}+\frac{M_{1}}{M_{1 \max }}\left(S_{t o p}-S_{1 t}\right)}{S_{t o p}} O_{1}\left(S_{1 t}\right)-M_{1}
\end{gathered}
$$

(c) if under (1) the strategy of the two enterprises is $\left(S_{1 t}, S_{2 t}\right)=(\neq 0,0)$, there are also two situations according to whether the opportunistic behaviors of enterprise 1 are found:

I The opportunistic behaviors of enterprise 2 are not found. The probability is

$$
1-\frac{S_{2 t}+\frac{M_{2}}{M_{2 \max }}\left(S_{t o p}-S_{2 t}\right)}{S_{t o p}} \text {. }
$$

The payoff enterprise 2 can get is

$$
W_{2}=(1-\alpha) Y+V-M_{1}+\left(\beta_{2 t}-1+\alpha\right) S_{2 t}
$$


The payoff enterprise 1 can get is

$$
W_{1}=\alpha Y+V-M_{2}-(1-\alpha) S_{2 t}
$$

II The opportunistic behaviors of enterprise 2 are found. The probability is $\frac{S_{2 t}+\frac{M_{2}}{M_{2 \max }}\left(S_{t o p}-S_{2 t}\right)}{S_{t o p}}$.

Under this condition, suppose enterprise 2 is punished and enterprise 1 is compensated. However, the network cooperation is ended and they cannot get the expected payoff.

The payoff enterprise 2 can get is

$$
W_{2}=\left(\beta_{2 t}-1+\alpha\right) S_{2 t}-O_{2}\left(S_{2 t}\right)-M_{1}
$$

The payoff enterprise 1 can get is

$$
W_{1}=-(1-\alpha) S_{2 t}+O_{2}\left(S_{2 t}\right)-M_{2}
$$

Therefore, under the condition of (c), the expected payoff of enterprise 1 and enterprise 2 is:

$$
\begin{aligned}
& W_{1}=\frac{S_{t o p}-\left[S_{2 t}+\frac{M_{2}}{M_{2 \max }}\left(S_{\text {top }}-S_{2 t}\right)\right]}{S_{\text {top }}}(\alpha Y+V) \\
& -(1-\alpha) S_{2 t}+\frac{S_{2 t}+\frac{M_{2}}{M_{2 \max }}\left(S_{t o p}-S_{2 t}\right)}{S_{\text {top }}} O_{2}\left(S_{2 t}\right)-M_{2} \\
& W_{2}=\frac{S_{\text {top }}-\left[S_{2 t}+\frac{M_{2}}{M_{2 \max }}\left(S_{t o p}-S_{2 t}\right)\right]}{S_{\text {top }}}[(1-\alpha) Y+V] \\
& +\left(\beta_{2 t}-1+\alpha\right) S_{2 t}-\frac{S_{2 t}+\frac{M_{2}}{M_{2 \max }}\left(S_{t o p}-S_{2 t}\right)}{S_{t o p}} O_{2}\left(S_{2 t}\right)-M_{1}
\end{aligned}
$$

(d) if under (1) the strategy of the two enterprises is $\left(S_{1 t}, S_{2 t}\right)=(\neq 0,0)$, and suppose the discovery events are independent, there are four situations according to whether the opportunistic behaviors of enterprise 1 and enterprise 2 are found:

I Both are not found. The probability is

$$
\left(1-\frac{S_{1 t}+\frac{M_{1}}{M_{1 \max }}\left(S_{t o p}-S_{1 t}\right)}{S_{t o p}}\right)\left(1-\frac{S_{2 t}+\frac{M_{2}}{M_{2 \max }}\left(S_{t o p}-S_{2 t}\right)}{S_{t o p}}\right) \text {. }
$$

Under this condition, the network can be maintained and the payoff of the two enterprises is:

$$
W_{1}=\alpha Y+V-M_{2}+\left(\beta_{1 t}-\alpha\right) S_{1 t}-(1-\alpha) S_{2 t}
$$




$$
W_{2}=(1-\alpha) Y+V-M_{1}-(1-\alpha) S_{1 t}+\left(\beta_{2 t}-1+\alpha\right) S_{2 t}
$$

II Enterprise 1 is found while enterprise 2 is not found. The probability is

$$
\left(\frac{S_{1 t}+\frac{M_{1}}{M_{1 \max }}\left(S_{t o p}-S_{1 t}\right)}{S_{t o p}}\right)\left(1-\frac{S_{2 t}+\frac{M_{2}}{M_{2 \max }}\left(S_{t o p}-S_{2 t}\right)}{S_{t o p}}\right)
$$

Enterprise 1 is punished and enterprise 2 is compensated. The network cooperation ends and the payoff of the two enterprises is:

$$
\begin{gathered}
W_{1}=\left(\beta_{1 t}-\alpha\right) S_{1 t}-(1-\alpha) S_{2 t}-O_{1} S_{1 t}-M_{2} \\
W_{2}=(1-\alpha) S_{1 t}+\left(\beta_{2 t}-1+\alpha\right) S_{2 t}+O_{1} S_{1 t}-M_{1}
\end{gathered}
$$

III Enterprise 2 is found while enterprise 1 is not. The probability is

$$
\left(1-\frac{S_{1 t}+\frac{M_{1}}{M_{1 \max }}\left(S_{t o p}-S_{1 t}\right)}{S_{\text {top }}}\right)\left(\frac{S_{2 t}+\frac{M_{2}}{M_{2 \max }}\left(S_{t o p}-S_{2 t}\right)}{S_{\text {top }}}\right) \text {. }
$$

Enterprise 2 is punished and enterprise 1 is compensated. The network cooperation is ended and the payoff of the two enterprises is:

$$
\begin{gathered}
W_{1}=\left(\beta_{1 t}-\alpha\right) S_{1 t}-(1-\alpha) S_{2 t}-O_{2} S_{2 t}-M_{2} \\
W_{2}=-(1-\alpha) S_{1 t}+\left(\beta_{2 t}-1+\alpha\right) S_{2 t}-O_{2} S_{2 t}-M_{1}
\end{gathered}
$$

IV Both enterprises are found out. The probability is

$$
\left(\frac{S_{1 t}+\frac{M_{1}}{M_{1 \max }}\left(S_{t o p}-S_{1 t}\right)}{S_{t o p}}\right)\left(\frac{S_{2 t}+\frac{M_{2}}{M_{2 \max }}\left(S_{t o p}-S_{2 t}\right)}{S_{t o p}}\right) .
$$

Both enterprises are punished and are compensated at the same time. The network is ended and the payoff the two enterprises can get is

$$
\begin{gathered}
W_{1}=\left(\beta_{1 t}-\alpha\right) S_{1 t}-(1-\alpha) S_{2 t}-O_{1} S_{1 t}+O_{2} S_{2 t}-M_{2} \\
W_{2}=-(1-\alpha) S_{1 t}+\left(\beta_{2 t}-1+\alpha\right) S_{2 t}+O_{1} S_{1 t}-M_{1}
\end{gathered}
$$

Thereby, under the condition of (d), the expected payoff enterprise 1 and enterprise 2 can get is

$$
W_{1}=\frac{S_{t o p}-\left[S_{1 t}+\frac{M_{1}}{M_{1 \max }}\left(S_{\text {top }}-S_{1 t}\right)\right] S_{\text {top }}-\left[S_{2 t}+\frac{M_{2}}{M_{2 \max }}\left(S_{t o p}-S_{2 t}\right)\right]}{S_{\text {top }}}(\alpha Y+V)
$$

$-M_{2}+\left(\beta_{1 t}-\alpha\right) S_{1 t}-(1-\alpha) S_{2 t}$ 


$$
\begin{aligned}
& -\frac{S_{1 t}+\frac{M_{1}}{M_{1 \max }}\left(S_{t o p}-S_{1 t}\right)}{S_{t o p}} O_{1}\left(S_{1 t}\right)+\frac{S_{2 t}+\frac{M_{2}}{M_{2 \max }}\left(S_{t o p}-S_{2 t}\right)}{S_{t o p}} O_{2}\left(S_{2 t}\right) \\
& W_{2}=\frac{S_{t o p}-\left[S_{1 t}+\frac{M_{1}}{M_{1 \max }}\left(S_{t o p}-S_{1 t}\right)\right] S_{t o p}-\left[S_{2 t}+\frac{M_{2}}{M_{2 \max }}\left(S_{t o p}-S_{2 t}\right)\right]}{S_{t o p}}[(1-\alpha) Y+V] \\
& -M_{1}-(1-\alpha) S_{1 t}+\left(\beta_{2 t}-1+\alpha\right) S_{2 t} \\
& +\frac{S_{1 t}+\frac{M_{1}}{M_{1 \max }}\left(S_{t o p}-S_{1 t}\right)}{S_{t o p}} O_{1}\left(S_{1 t}\right)-\frac{S_{2 t}+\frac{M_{2}}{M_{2 \max }}\left(S_{t o p}-S_{2 t}\right)}{S_{t o p}} O_{2}\left(S_{2 t}\right)
\end{aligned}
$$

3.3.2. The equilibrium Influenced by Opportunism, Trust, Supervision and Punishment

From above analysis, we can see no matter which enterprise takes on opportunistic behaviors, it will lead to the failure of the network in certain probability. Therefore, only when $\left(S_{1 t}, S_{2 t}\right)=(0,0)$, the network is stable. Next, we consider when the trust level of the network is $S_{b}$, whether the network can reach the equilibrium.

When $S_{2 t}=0$, the enterprise 1 must consider whether to take on opportunistic behaviors and which strategy is more beneficial. The difference between the payoff enterprise 1 can get under the condition of $S_{1 t} \neq 0$ and $S_{1 t}=0$ is:

$$
\begin{aligned}
\Delta W_{1}=\frac{S_{t o p}-\left[S_{1 t}+\frac{M_{1}}{M_{1 \max }}\left(S_{t o p}-S_{1 t}\right)\right]}{S_{t o p}}(\alpha Y+V)+\left(\beta_{1 t}-\alpha\right) S_{1 t} \\
-\frac{S_{1 t}+\frac{M_{1}}{M_{1 \max }}\left(S_{t o p}-S_{1 t}\right)}{S_{\text {top }}} O_{1}\left(S_{1 t}\right)-M_{2}-\left(\alpha Y+V-M_{2}\right) \\
=\frac{-\left[S_{1 t}+\frac{M_{1}}{M_{1 \max }}\left(S_{t o p}-S_{1 t}\right)\right]}{S_{t o p}}(\alpha Y+V)+\left(\beta_{1 t}-\alpha\right) S_{1 t} \\
-\frac{S_{1 t}+\frac{M_{1}}{M_{1 \max }}\left(S_{t o p}-S_{1 t}\right)}{S_{t o p}}\left(a_{p} S_{1 t}+b_{p}\right) \\
=\frac{-\left[\left(M_{1 \max }-M_{1}\right)(\alpha Y+V) S_{1 t}+(\alpha Y+V) M_{1} S_{t o p}\right]}{M_{1 \max } S_{t o p}}+\frac{\left(\beta_{1 t}-\alpha\right) M_{1 \max } S_{t o p} S_{1 t}}{M_{1 \max } S_{t o p}} \\
-\frac{\left[\left(M_{1 \max }-M_{1}\right) a_{p} S_{1 t}^{2}+M_{1} S_{t o p} a_{p} S_{1 t}+b_{p}\left(M_{1 \max }-M_{1}\right) S_{1 t}+M_{1} S_{t o p} b_{p}\right]}{M_{1 \max } S_{t o p}}
\end{aligned}
$$




$$
\begin{aligned}
& =\frac{-\left(M_{1 \max }-M_{1}\right) a_{p} S_{1 t}^{2}}{M_{1 \max } S_{t o p}} \\
& \frac{S_{1 t}\left[-\left(M_{1 \max }-M_{1}\right)\left(\alpha Y+V+b_{p}\right)+\left(\beta_{1 t}-\alpha\right) M_{1 \max } S_{t o p}-M_{1} S_{\text {top }} a_{p}\right]}{M_{1 \max } S_{\text {top }}}
\end{aligned}
$$

$-\frac{(\alpha Y+V) M_{1} S_{t o p}+M_{1} S_{t o p} b_{p}}{M_{1 \max } S_{t o p}}$

The pole of $\Delta W_{1}$ at the real number axis is

$$
\left\{\begin{array}{l}
\frac{-\left(M_{1 \max }-M_{1}\right)\left(\alpha Y+V+b_{p}\right)+\left(\beta_{1 t}-\alpha\right) M_{1 \max } S_{t o p}-M_{1} S_{t o p} a_{p}}{2\left(M_{1 \max }-M_{1}\right) a_{p}}, \\
\frac{\left[-\left(M_{1 \max }-M_{1}\right)\left(\alpha Y+V+b_{p}\right)+\left(\beta_{1 t}-\alpha\right) M_{1 \max } S_{t o p}-M_{1} S_{t o p} a_{p}\right]^{2}}{4\left(M_{1 \max }-M_{1}\right) M_{1 \max } a_{p} S_{t o p}}-\frac{M_{1}\left(\alpha Y+V+b_{p}\right)}{M_{1 \max }}
\end{array}\right\}
$$

Therefore, the condition for the biggest value of $\Delta W_{1}$ in $\left[0, S_{t o p}\right]$ being smaller than the degree of trust $S_{b}$ is (1)

$$
-\frac{\left(M_{1 \max }-M_{1}\right)\left(\alpha Y+V+b_{p}\right)}{M_{1 \max }}+\left(\beta_{1 t}-\alpha\right) S_{t o p}-\frac{M_{1}}{M_{1 \max }} S_{t o p} a_{p}<0
$$

Or (2)

$$
\left\{\begin{array}{l}
\frac{-\left(M_{1 \max }-M_{1}\right)\left(\alpha Y+V+b_{p}\right)+\left(\beta_{1 t}-\alpha\right) M_{1 \max } S_{t o p}-M_{1} S_{t o p} a_{p}}{2\left(M_{1 \max }-M_{1}\right) a_{p}}>S_{t o p} \\
-(\alpha Y+V)-b_{p}+\left(\beta_{1 t}-\alpha-a_{p}\right) S_{t o p}<S_{b}
\end{array}\right.
$$

Or (3)

$$
\left\{\begin{array}{l}
0<\frac{-\left(M_{1 \max }-M_{1}\right)\left(\alpha Y+V+b_{p}\right)+\left(\beta_{1 t}-\alpha\right) M_{1 \max } S_{t o p}-M_{1} S_{\text {top }} a_{p}}{2\left(M_{1 \max }-M_{1}\right) a_{p}}<S_{\text {top }} \\
\frac{\left[-\left(M_{1 \max }-M_{1}\right)\left(\alpha Y+V+b_{p}\right)+\left(\beta_{1 t}-\alpha\right) M_{1 \max } S_{t o p}-M_{1} S_{t o p} a_{p}\right]^{2}}{4\left(M_{1 \max }-M_{1}\right) M_{1 \max } a_{p} S_{t o p}}-\frac{M_{1}\left(\alpha Y+V+b_{p}\right)}{M_{1 \max }}<S_{b}
\end{array}\right.
$$

Similarly, we can know the strategies of enterprise 2.

Condition (1) can be transformed to $\left(\beta_{1 t}-\alpha\right) S_{t o p}<\frac{\left(M_{1 \max }-M_{1}\right)\left(\alpha Y+V+b_{p}\right)}{M_{1 \max }}+\frac{M_{1}}{M_{1 \max }} S_{t o p} a_{p}$. That is to say, when the comprehensive effect of supervision, punishment and the possible payoff loss is bigger than the biggest payoff from the opportunistic behaviors, no matter the trust level in the network, none of the members will take on opportunistic behavior. For example, members of the American semiconductor industry technology alliance project always cooperate with each other in the R\&D field. Some of them are also member enterprises in the same modular production networks. In fact, it is popular in modular production networks for the manufacturing integrators to work with some of the large module suppliers to undertake R\&D together to set industrial standards. Usually, before the 
cooperation, the alliance project will examine the goal and ensure that both sides have the basic capability to achieve this goal. During the cooperation, the alliance project will provide consultation service and do an audit. Such kind of strict third party supervision greatly facilitates the success of the cooperation [29]. No matter whether these enterprises are competitive or complementary with each other, that is, no matter the trust level in the network, all the participants will hardly take on opportunistic behavior.

Condition (2) shows if there is not enough supervision and punishment within the network, the enterprise will damage certain common payoffs in return for more private payoffs. Then, member enterprises in the network will damage the common payoff to the utmost degree. However, the trust level in the network is very high. Therefore, no member enterprises will take on opportunistic behaviors in the end. For example, in December 2004, Fangtek Ltd. and Semiconductor Manufactory International Corporation (SMIC) signed a strategic cooperation agreement to enhance their cooperation in chip design and chip manufacturing. Then, SMIC became an important OEM partner for Fangtek Ltd. and began to provide the turnkey solutions of advanced chips for Fangtek Ltd. For Fangtek Ltd., through this cooperation, it can obtain technical support for silicon wafer production and chip production from SMIC. Because of the complementarity of their technology and high dependence on each other, the trust level between these two enterprises is relatively high. Although in their cooperation there is no supervision and punishment mechanism, the cooperation still progresses smoothly with few opportunistic behaviors on both sides.

Condition (3) shows the degree of supervision and punishment in the network is very closely related to the opportunistic efficiency of member enterprises. There is an optimal opportunistic behavior. If the network wants to be stable, the trust level must be higher than the payoff from the optimal opportunistic behavior. Take the cooperation of Freescale, Philips and STMicroelectronics as an example. In their cooperation, each side was responsible for a certain $R \& D$ component of the production of $300 \mathrm{~nm}$ wafer. For instance, STMicroelectronics was mainly responsible for finding the optimization method for the bonding point. After it successfully did this, STMicroelectronics could have chosen to partly release the optimization method, that is, taking on opportunistic behavior and not sharing all the knowledge, which might make the cooperation very unstable. However, the fact is that STMicroelectronics chose to fully release the knowledge and built trust with other members. This is mainly because STMicroelectronics has realized that building high trust with others can further enhance their cooperation and the cooperation can bring a continuous flow of benefits. Therefore, it would not easily betray trust just for the short-term benefits it may receive by behaving opportunistically.

On the whole, from the results of the model, we can see that the supervision and punishment in networks can be substituted for each other to some degree. Increasing supervision can increase the probability of finding opportunism while increasing punishment can increase deterrence. Furthermore, punishment can be divided into two parts: the fixed part and the variable part. The fixed part can influence the potential payoff of the network while the variable part is closely related to the range of opportunistic behaviors and we can adjust its strength according to the degree of opportunism. Supervision leads to costs. Therefore, we must ensure the feasibility of supervision. At the same time, because the stability of semiconductor modular production networks is influenced by many factors and the initial supervision terms cannot guarantee everything, we need to effectively manage supervision and punishment to make sure there is a proper ratio between them. 


\section{Conclusions}

For semiconductor enterprises, establishing and maintaining effective modular production networks is one of the key paths to building competitive advantage. Based on the above game analysis, we can find that the allocation of common benefits, the fluctuation in external markets, and the establishment of trust between member enterprises can exert great influence on the stability of semiconductor modular production networks. The analysis of the three aspects provides valuable theoretical basis for building stable and effective semiconductor modular production networks.

In the interest allocation aspect, according to the analysis, when there is market fluctuation, the greater the benefits the member enterprise can derive from common interests, the more likely it is the member enterprise will not exit the modular production network. If the member enterprises of the semiconductor modular production network want to obtain a larger share of interests, they have to improve their own negotiation ability. For Chinese semiconductor enterprises, enhancing the negotiation ability in global modular production network cannot be achieved overnight. A suggested strategy for them is to give priority to the development of the semiconductor design industry. Comparing with the other three modules (manufacturing, packaging and testing), chip design is an upstream industry, which requires high technology, small capital investment and a strong market. China has a huge market and is rich in human resources, which matches the development requirements of the chip design industry. Therefore, it is possible for Chinese semiconductor enterprises to first make a breakthrough in this field. Generally speaking, chip design enterprises are following the chip manufacturing enterprises closely. There is a cluster of chip design enterprises centered on the large chip manufacturing enterprises. The improvement of the manufacturing ability of Chinese semiconductor enterprises also lays a solid foundation for a breakthrough in the chip design industry. What is more, member enterprises need to formulate a proper network interest allocation mechanism based on several rounds of negotiations. With the changes in the positions of members in the network, the interest allocation mechanism needs to change correspondingly.

In terms of market fluctuation, based on the above analysis, we need to enhance the adaptive ability of networks to the external environment. For example, at present, the import of chip equipment used for the manufacturing of baseband and missile aiming systems in China from abroad is largely restricted. If the Chinese equipment industry can get the support of the domestic chip enterprises to develop a local, stable supply of advanced equipment, the Chinese semiconductor enterprises can avoid the licensing problem of importing from abroad. In this way, the market can introduce more competition, reduce the price of equipment and therefore reduce dependence on the external market. Furthermore, the semiconductor enterprises should have a comprehensive grasp of the market and adjust the production of networks accordingly. When the growth of global semiconductor production slows down, the inland semiconductor market of China keeps flourishing. According to the supply-demand statistics and tendency forecast of the Chinese semiconductor industry, the output gap in 2013 was about six billion dollars. The main problem we have is not over-capacity of production but the huge semiconductor trade deficit caused by the gap between production and supply-demand. Generally speaking, if market capacity and industry scale increase synchronously, technology will be improved greatly. Therefore, according to the scientific market evaluation and forecast, establishing production 
factories in a planned way and enlarging the production scale can enhance the adaptive ability of networks to the external environment.

In terms of trust management, for modular production networks, the biggest advantage of modular production networks is that the member enterprises can master more new technologies through "back to back" competitive learning and introductions to complementary technologies, talents and markets to enhance the enterprise's competitive position. Trust management is necessary for a modular production network. No doubt, it will benefit the future development of the whole network. Before constructing a production network, enterprises should first build a large commercial network. The large commercial network refers to an enterprise cooperating with other business bodies outside of the network. By expanding the commercial network, member enterprises can have broad and smooth flow of information, overcome the weakness of asymmetry of information, enlarge its influence, possess strong negotiation abilities, and learn more about their potential partners such as their reputation and cooperation levels and therefore build trust. Secondly, networks should establish the code of conduct with which each member will comply. This is because a set of good codes of conduct can help members to form values and ideas all members approve of and comply with. Then, a good network culture and values will be continuously assimilated and learned by members and help to form a set of operation modes and the basic principles of interest allocation.

Based on game models, this paper analyzes the mechanism of how main factors influence the stability of semiconductor modular production networks, and aims to provide valuable guidance for establishing and maintaining a stable and effective modular production network. However, this paper also has some shortcomings. For example, this paper has not provided the statistical proof for the selection of the key factors to construct the models. In addition, if the analysis of main factors is based on the analysis of the formation and development process of modular production networks, the stability analysis will be more comprehensive and convincing. Future study should focus on the selection of main factors and simulation of the game models.

\section{Acknowledgments}

This work is supported by the NSFC (71361013, 71163014), and The Education Department of Jiangxi province science and technology research projects (11728).

\section{Author Contributions}

The corresponding author Wei He is responsible for the design and writing of the whole paper. The co-author Si-hua Chen is responsible for the game model establishment.

\section{Conflicts of Interest}

The authors declare no conflict of interest.

\section{References}

1. Baldwin, C.Y.; Clark, K.B. Managing in an age of modularity. Har. Bus. Rev. 1997, 75, 84-93.

2. Langlois, R.N. Modularity in technology and organization. J. Econ. Behav. Organ. 2002, 49, $19-37$. 
3. Langlois, R.N.; Robertson, P. Networks and innovation in a modular system: Lessons from microcomputer and stereo components industries. Res. Pol. 1992, 21, 297-313.

4. Sanchez, R.; Mahoney, J.T. Modularity, flexibility, and knowledge management in product and organizational design. Strat. Manag. J. 1996, 17, 63-76.

5. Sturgeon, T.J. Modular production networks: A new American model of industrial organization. Ind. Corp. Change 2002, 11, 451-496.

6. Podolny, J.M.; Smart, T.E.; Hannan, M.T. Networks, knowledge, and niches: Competition in the worldwide semiconductor industry, 1984-1991. Am. J. Sociol. 1997, 102, 659-689.

7. Jiang, G.; He, P. On stability and reliability of a universal decision making system. J. Southwest Jiaotong Univ. 1999, 34, 47-50.

8. Yu, Y.; Jia, H.; Li, P.; Su, J. Power system instability and chaos. Electr. Pow. Syst. Res. 2003, 65, 187-195.

9. Clarke, B.L. Stability of Complex Reaction Networks; John Wiley \& Sons: New York, NY, USA, 1980; pp. 302-355.

10. Sun, R.; Li, Q.; Niu, C. Ecology; Science Press: Beijing, China, 2000; pp. 109-131.

11. Dashkovskiy, S.; Gorges, M.; Kosmykov, M.; Mironchenko, A.; Naujok, L. Modeling and stability analysis of autonomously controlled production networks. Log. Res. 2011, 3, 145-157.

12. Jackson, M.O. A survey of network formation models: Stability and efficiency. In Group Formation in Economics: Networks, Clubs, and Coalitions; Demange, G., Wooders, M., Eds.; Cambridge University Press: Cambridge, MA, USA, 2005; pp. 11-58.

13. Scholz-Reiter, B.; Wirth, F.; Freitag, M.; Dashkovskiy, S.; Jagalski, T.; de Beer, C.; Ruffer, B. Some remarks on the stability of manufacturing logistic networks. In Operations Research Proceedings; Haasis, H.D., Kopfer, H., Schonberger, J., Eds.; Springer: Berlin, Germany, 2006; pp. 91-96.

14. Choi, T.Y.; Dooley, K.J.; Rungtusanatham, M. Supply networks and complex adaptive systems: Control versus emergence. J. Oper. Manag. 2001, 19, 351-356.

15. Morana, R.; Seuring, S. A three level framework for closed-loop supply chain management—Linking society, chain and actor level. Sustainability 2011, 3, 678-691.

16. Haynes, J.; Cubbage, F.; Mercer, E.; Sills, E. The search for value and meaning in the cocoa supply chain in Costa Rica. Sustainability 2012, 4, 1466-1487.

17. Warfield, J.N. Twenty laws of complexity: Science applicable in organizations. Syst. Res. Behav. Sci. 1999, 16, 3-40.

18. Hennart, J.F. A transaction cost theory of equity joint ventures. Strateg. Manag. J. 1988, 9, 361-374.

19. Gulati, R. Does familiar breed trust? The implication of repeated ties for contractual choice in alliance. Acad. Manag. J. 1995, 38, 85-112.

20. Tailan, C. Strategic trading in strategic resources: Necessary conditions, transaction cost problems, and choice of exchange structure. Manag. J. 1994, 15, 271-290.

21. Khan, A.S. Understanding global supply chains and seafood markets for the rebuilding prospects of northern gulf cod fisheries. Sustainability 2012, 4, 2946-2969.

22. Lutz, J.; Schachinger, J. Do local food networks foster socio-ecological transitions towards food sovereignty? Learning from real place experiences. Sustainability 2013, 5, 4778-4796.

23. Burt, R.S. Structural Holes; Harvard University Press: Cambridge, MA, USA, 1992; pp. 195-236. 
24. Podolny, J.M. A status-based model of market competition. Am. J. Sociol. 1993, 98, 829-872.

25. Foley, M.W.; Edwards, B. Is it time to disinvest in social capital? J. Public Pol. 1999, 19, 141-173.

26. Podolny, J.M. Market uncertainty and the social character of economic exchange. Admin. Sci. $Q$. 1994, 39, 458-483.

27. Baker, W.E.; Iyer, A. Information networks and market behavior. J. Math. Sociol. 1992, 16, 305-332.

28. Chen, F.-Q. The evaluation system of private payoff and common payoff of enterprise alliance. Sci. Res. Manag. 2002, 4, 35-46.

29. Yu, J.-T.; Wu, C.-Y. Case study on the management of enterprise joint R\&D project. Sci. Res. Manag. 2005, 26, 65-72.

(C) 2014 by the authors; licensee MDPI, Basel, Switzerland. This article is an open access article distributed under the terms and conditions of the Creative Commons Attribution license (http://creativecommons.org/licenses/by/3.0/). 